\title{
Coexistence of a single cerebral arteriovenous malformation and spinal arteriovenous malformation
}

\author{
Yabing Wang, Hongqi Zhang, Feng Ling \\ Department of Neurosurgery, Xuanwu Hospital, 45\#, ChangChun Ave, Beijing - 100 053, PR. China
}

\section{Address for correspondence: Dr. Feng Ling, \\ Department of Neurosurgery, Xuanwu Hospital, 45\#, ChangChun Ave, Beijing - 100 053, PR. China. \\ E-mail: ling-feng@yahoo.com}

\begin{abstract}
The coexistence of a cerebral and a spinal arteriovenous malformation (AVM) together is extremely rare. We present a 31 -year-old woman, who suffered from severe root pains in the left upper extremity. Magnetic resonance imaging (MRI) revealed the abnormal vessels in the left occipital lobe and upper cervical segment of spinal cord. Cerebral angiography and spinal angiogram revealed two AVMs: One was in the right occipital lobe and the other was located in the C1-C2 segments of cervical cord. She had no other vascular lesions, and nor did her other family members. As the primary problem in her was left upper extremity root pains, which we considered was related to the spinal AVM, the first therapeutic treatment was focused on spinal AVM. The cerebral AVM of the right occipital lobe was surgically resected after part embolization.
\end{abstract}

Key words: Multiple; cerebral arteriovenous malformation; spinal arteriovenous malformations

\section{Introduction}

Coexistence of cerebral arteriovenous malformation $(\mathrm{AVM})$ and spinal AVM is extremely rare. Since the first description in 1969, to the best of our knowledge, no more than 10 cases with single cerebral AVM combined with a single spinal AVM have been documented. We viewed all the 697 cases spinal vascular malformation since 1990 in our center; only one case was confirmed with single cerebral AVM and a spinal AVM, thus giving an incidence of $0.14 \%$ of concurrence of single cerebral AVM and a spinal AVM.

\section{Case Report}

A 31-year-old woman presented with severe root pain of the left upper extremity since 2001. On the first admission in December 2006, magnetic resonance imaging (MRI) revealed abnormal vessels in the spinal cord at $\mathrm{C} 2$ level and an abnormal lesion, a flow void signal in the right occipital lobe [Figure 1A and B]. Spinal and cerebral angiogram revealed a spinal arteriovenous malformation intramedullary at C2 segment and a cerebral AVM of the right occipital lobe [Figure 2a-d]. The bilateral vertebral arteries, mostly the anterior spinal arteries from the left vertebral artery, fed the spinal AVM. The draining veins were into the veins located at the dorsal aspect of the cervical spinal cord. Left vertebral angiogram also demonstrated the right occipital cerebral AVM, mainly fed by the right posterior cerebral artery and drained into the superior sagittal sinus. The symptom of this patient was root pain of the left upper extremity, which we considered related to the spinal AVM located at the C2 segment. The spinal AVM was embolized using microsphere (300-500 $\mu \mathrm{m}$ ) under local anesthesia. Postembolization angiography demonstrated a significant reduction in blood flow from the left vertebral artery to the AVM [Figure 3a]. Several days later she had C1-C2 laminectomy and resection of the spinal AVM. Most of the AVM was intramedullary. The postoperative course was uncomplicated with no neurological deficits, and the root pain of the upper extremty gradually improved with carbamazepine over one week. The 


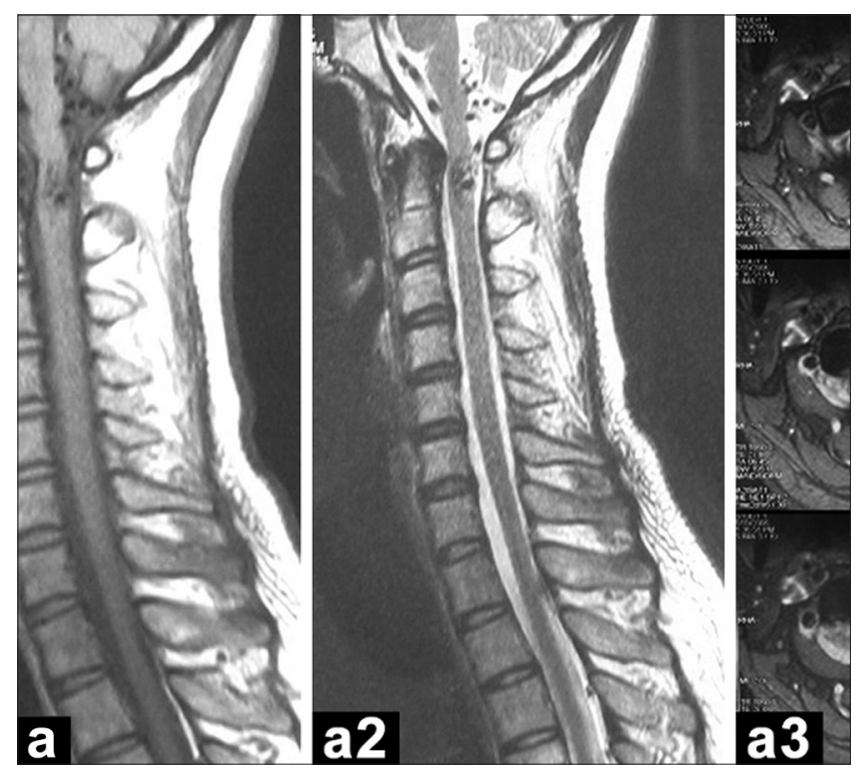

Figure 1A: Magnetic resonance imaging scans of the cervical segment of spinal cord (Dec, 2006). It revealed the arteriovenous malformation (arrow) located at the C1-C2 level, and there also existed vessel void signal (arrow head) at the dorsal aspect of the spinal cord; and the axial image revealed the lesion was an intramedullary arteriovenous malformation
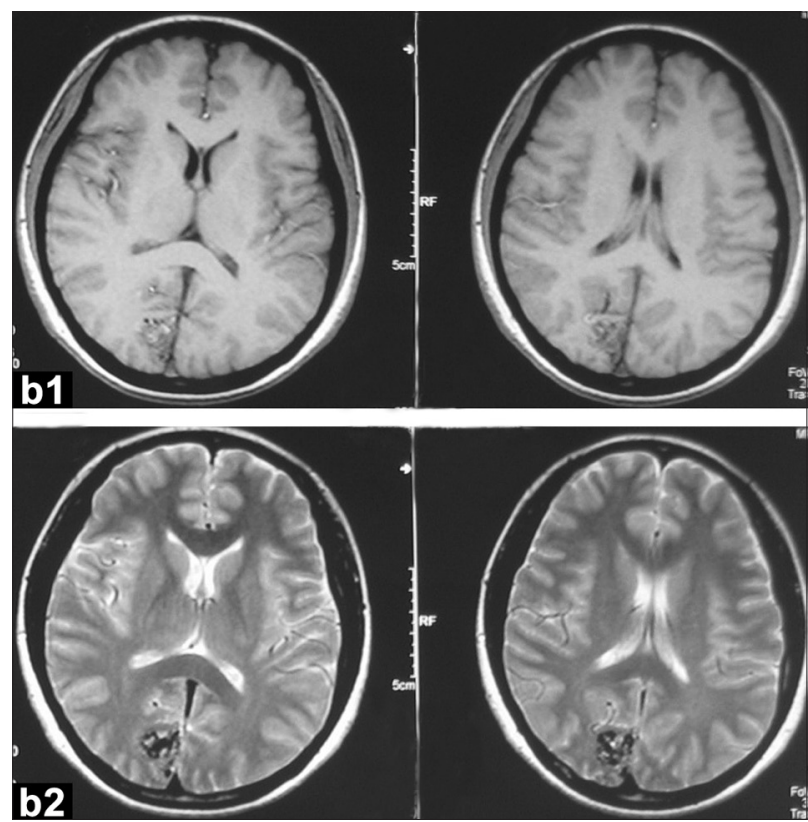

Figure 1B: Head magnetic resonance imaging (Dec, 2006), which revealed the cerebral arteriovenous malformation located at the medial surface of the right occipital lobe
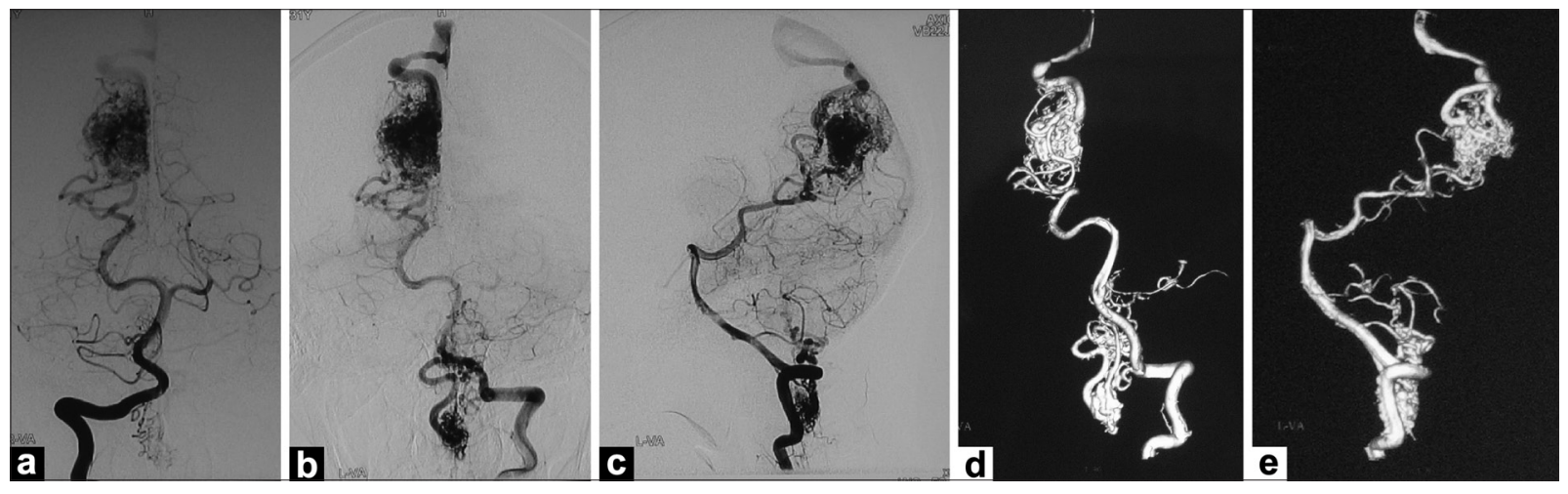

Figure 2: (a and b) The anteroposterior view of left and right vertebral arteriogram (Dec, 2006); (c) Lateral view of right vertebral angiogram (Dec, 2006). This spinal arteriovenous malformation was fed by the bilateral vertebral artery, mainly supplied by the anterior spinal arteries from the left vertebral artery and drained into the veins located at the dorsal side of the cervical spinal cord. Left vertebral angiography also demonstrated the right occipital cerebral arteriovenous malformation, which was fed by the right parietoccipital artery and calcarine artery and drained into the superior sagittal sinus. (d and e) 3D angiogram of the left vertebral angiogram shows the two arteriovenous malformations clearly

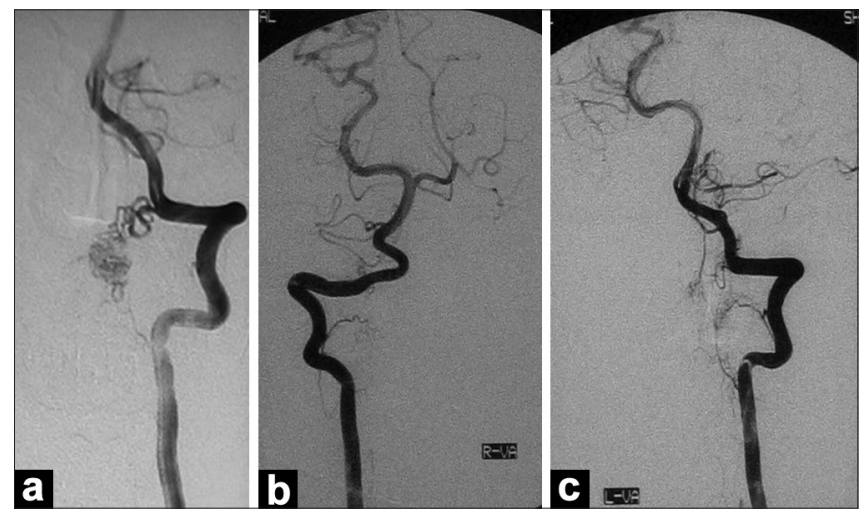

Figure 3: (a) Left vertebral angiogram (Dec,2006): Post-embolization angiogram with microsphere $(300-500 \mu \mathrm{m})$, blood flow of the spinal arteriovenous malformation decreased obviously compared with the former angiogram in Figure 2; (b and c) Bilateral vertebral angiogram (Dec, 2006) demonstrated the spinal arteriovenous malformation had been removed totally after surgery by C1-C2 laminectomy left vertebral angiogram revealed no obvious residual nidus [Figure $3 \mathrm{~b}$ and $\mathrm{c}$ ].

The patient recovered well after the operation of the spinal AVM, but as we felt she still faced the risk of bleeding due to the cerebral AVM of the right occipital lobe, in consultation with the patient and her relatives she was readmitted for the treatment of the cerebral AVM in May 2007. Part embolization with Glubran 2 for the cerebral AVM before the surgery was performed [May 2007, Figure 4a-d], and the cerebral AVM was totally excised by the right parietal-occipital craniotomy. Postoperatively she had good recovery without any neurological deficits. She had follow-up vertebral angiogram [Figure 5] and MRI [including the cervical segment and head, Figure 6] in December 2008. 

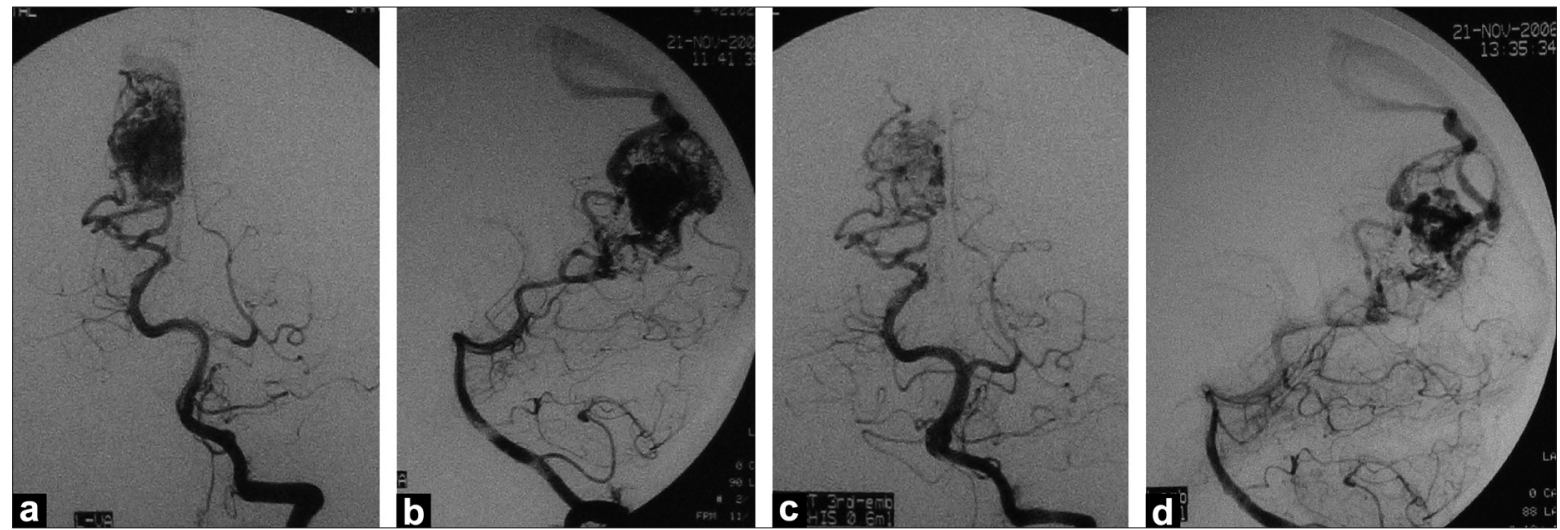

Figure 4: (a,b) Left vertebral angiogram (AP and lateral view, May 2007): Pre-embolization angiogram of the right occipital arteriovenous malformation, supplied by right parietoccipital artery and calcarine artery; (c,d): Post-embolization angiogram (May 2007) with Glubran 2, blood flow of the CAVM decreased obviously, which could make it safer for the surgery
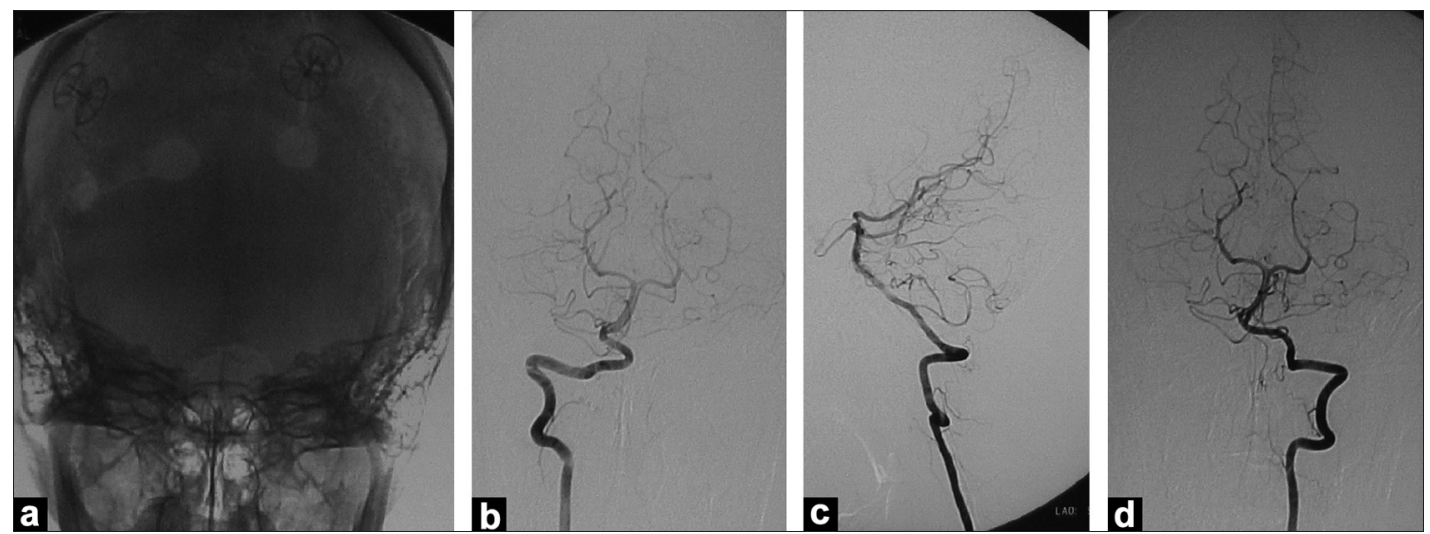

Figure 5: (a) Plane skull x-ray film 19-month follow-up (Dec, 2008) after right parietal-occipital craniotomy for the surgery removal of the CAVM; (b and c) AP and lateral view of the left vertebral angiogram (Dec, 2008) (d) AP view of right VA angiogram. Both of the CAVM (right occipital lobe, 19-month follow-up) and the SAVM (C1-C2 level) vanished (2 years follow-up after surgery), no obvious residual nidus could be observed

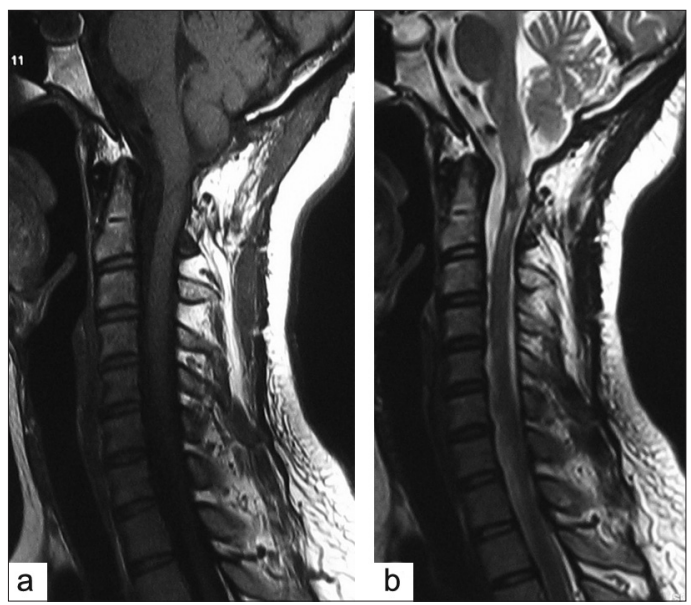

Figure 6A: Magnetic resonance imaging scans of the cervical segment of spinal cord (Dec, 2008), 2 years follow-up after surgery (Dec, 2006)

\section{Discussion}

The occurrence of multiple AVMs in the central nervous system is rare. ${ }^{[2-4]}$ Furthermore, single cerebral AVM combined with a spinal AVM is extremely rare and the
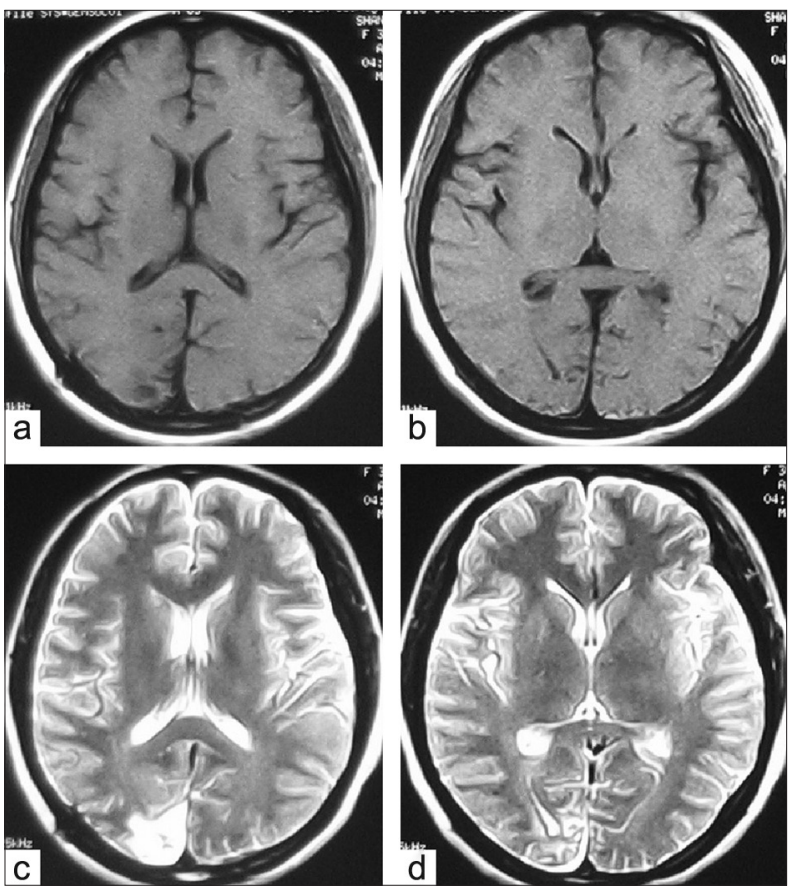

Figure 6B: Head magnetic resonance imaging (Dec, 2008), 19-month follow-up after surgery (May, 2007) 


\begin{tabular}{|c|c|c|c|c|}
\hline Author & Age & Sex & $\begin{array}{l}\text { Location of } \\
\text { AVM }\end{array}$ & Symptom \\
\hline $\begin{array}{l}\text { Kraycnbuhl, } \\
\text { et al. }{ }^{[1]}\end{array}$ & 55 & NA & $\begin{array}{l}\text { Cerebellum } \\
\text { T2-L2 }\end{array}$ & $\begin{array}{l}\text { No symptom } \\
\text { leg weakness }\end{array}$ \\
\hline Hash, et al..$^{[2]}$ & 24 & $M$ & Rt. tent T9-10 & SAH \\
\hline $\begin{array}{l}\text { Hoffman, } \\
\text { et al. }{ }^{[3]}\end{array}$ & 3 & $M$ & Rt. temp T2-10 & $\begin{array}{l}\text { SAH leg } \\
\text { weakness }\end{array}$ \\
\hline $\begin{array}{l}\text { Parkinson, } \\
\text { et al. }{ }^{[4]}\end{array}$ & 47 & $M$ & Lt. temp.T12-L1 & $\mathrm{SAH}$ \\
\hline \multirow[t]{2}{*}{ Moss, et al. ${ }^{[6]}$} & $\begin{array}{l}\text { Rt. cau. } \\
50\end{array}$ & $\mathrm{~F}$ & $\begin{array}{l}\text { Lt. front. P.-M. } \\
\text { junction }\end{array}$ & Autopsy case \\
\hline & T6-7 & & & \\
\hline $\begin{array}{l}\text { Mizutani, } \\
\text { et al. }{ }^{[7]}\end{array}$ & 7 & $\mathrm{~F}$ & Cerebellum T6-7 & $\mathrm{ICH}$ \\
\hline \multirow[t]{2}{*}{$\begin{array}{l}\text { Tsurushima, } \\
\text { et al. }{ }^{[8]}\end{array}$} & 3 & $\mathrm{~F}$ & Left temporal L2 & SAH IVH \\
\hline & Rt. front. (4) & & & \\
\hline \multirow[t]{2}{*}{$\begin{array}{l}\text { S. asegawa, } \\
\text { et al. }{ }^{[9]}\end{array}$} & 22 & $M$ & $\begin{array}{l}\text { Rt. temp. (2) Lt. } \\
\text { occip. ( } 2 \text { ) }\end{array}$ & $\mathrm{ICH}$ \\
\hline & L1 & & & \\
\hline Our case & 31 & $\mathrm{~F}$ & $\begin{array}{l}\text { Rt. occipital lobe } \\
\text { C1-C2 segment }\end{array}$ & Root pain \\
\hline
\end{tabular}

C - Cervical; T - Thoracic; L - Lumbar; SAH - Subarachnoid hemorrhage; $\mathrm{ICH}$ - Intracranial hemorrhage; IVH - Intraventricular hemorrhage;

Tent - Tentorium; Front - Frontal; Temp - Temporal; Occip - Occipital; Cau - Caudate nucleus; P-M - Ponto-medullary; N.A. - Not available

exact incidence is unknown. Up to now, not more than 10 such cases, single cerebral AVM combined with a single spinal AVM, have been reported since 1969. ${ }^{[1]}$ Clinical details of the nine cases reported in the literature and our case are summarized in Table $1 .{ }^{[1-4,6-9]}$ As compared to the other reported cases, the same artery the vertebral artery fed the two AVMs in our patient. In the other reported cases, the AVMs were fed by different artery system.

Willinsky ${ }^{[5]}$ reported a $3.9 \%$ incidence of multiple cerebral AVMs by reviewing the angiograms of 203 patients. In our center, the incidence of concurrence of single cerebral AVM and a spinal AVM is about $0.14 \%$ (1/697).
The natural history of multiple AVMs remains unclear. At present there is no consensus regarding the appropriate treatment in patients with multiple AVMs and embolization has been suggested as a useful method combined with the surgical treatment in patients with multiple AVMs. The therapeutic strategy for multiple AVMs remains difficult. Based on our experience, we suggest a staged approach.

\section{References}

1. Kraycnbuhl H, Yasargil MG, McClintock HG. Treatment of spinal cord vascular malformations by surgical excision. J Neurosurg 1969;30:427-35.

2. Hash C.J, Grossman CB, Shenkin HA. Concurrent intracranial and spinal cord arteriovenous malformations. Case report. J Neurosurg 1975;43:104-7.

3. Hoffman HJ, Mohr G, Kusunoki T. Multiple arteriovenous malformation of spinal cord and brain in a child. Childs Brain 1976;2:317-24.

4. Parkinson D, West M. Spontaneous subarachnoid hemorrhage first from an intracranial and then from a spinal arteriovenous malformation. Case report. J Neurosurg 1977;47:965-8.

5. Willinsky RA, Lasjaunias P, Terbrugge K, Burrows P. Multiple cerebral arteriovenous malformations. Review of our experience from 203 patients with cerebral vascular lesions. Neuroradiology 1990;32:207-10.

6. Moss JG, Sellar RJ, Hadley DM. Intracerebral and spinal vascular malformation in a patient without hereditary haemorrhagic telangiectasia. Neuroradiology 1989;31:280-1.

7. Mizutani T, Tanaka H, Aruga T. Multiple arteriovenous malformations located in the cerebellum, posterior fossa, spinal cord, dura, and scalp with associated portwine stain and supratentorial venous anomaly. Neurosurgery 1992;31:137-40.

8. Tsurushima H, Meguro K, Matsumura A, Narushima K, Nakada Y, Nose T. Multiple Arteriovenous Malformations of Spinal Cord and Brain in a Child. Pediatr Neurosurg 1995;23:166-70.

9. Hasegawa S, Hamada JI, Morioka M, Kai Y, Takaki S, Ushio Y. Multiple Cerebral Arteriovenous Malformations (AVMs) Associated with Spinal AVM. Acta Neurochir (Wien) 1999;141:315-9.

Accepted on 23-10-2009

Source of Support: Nil, Conflict of Interest: None declared. 